\title{
Composition and Temperature of the Upper Atmosphere
}

$\mathrm{O}^{\mathrm{x}}$ May 4, in the lecture theatre of the Royal Institution in London, a joint discussion on the upper atmosphere was held by the Chemical Society, the Physical Society, and the Royal Meteorological Society. Instead of attempting to cover the whole subject, it was thought advisable to confine the discussion to topics in which the sciences represented by these societies were equally interested : chemical composition, density, and temperature. The electrical state of the upper atmosphere, the study of which is exclusively the domain of the physicist, was for example touched upon only in so far as it has a bearing on the subjects mentioned. Six speakers had been invited briefly to introduce various aspects, and after their contributions a general discussion was opened. Time permitted only a statement of experimental results; their theoretical explanation would probably be an appropriate subject for another meeting.

Prof. F. A. Paneth (Durham) reviewed recent attempts towards the direct chemical investigation of the stratosphere. This research was undertaken in order to decide to what extent the air of the strato. sphere can be considered as being at rest; if it be fairly undisturbed by convective currents, then we should expect to find in the stratosphere the percentage of the lighter gases increased at the expense of the heavier ones. Two gases have been used for this comparison: the 'light' gas helium and the 'heavy' gas oxygen. (In the case of helium a special survey had first to be carried out to prove that on the surface of the earth its abundance shows no variations.) The results of the two dozen or so analyses so far made in England, Russia, Germany and the United States indicate that the helium and oxygen content is constant throughout the troposphere, and in the stratosphere up to about $20 \mathrm{~km}$. ; but that above this height the amount of helium is greater, and of oxygen smaller, by a few per cent. Even above $20 \mathrm{~km}$. there is, however, no regular increase of this change in composition with height. The obvious conclusion is that in these layers diffusive separation of lighter and heavier gases makes itself felt, but that the atmosphere is still far from being undisturbed by turbulence.

It was mentioned that the three gases which are present in the troposphere in varying concentration, namely water vapour, radon, and ozone, lend themselves also to direct chemical investigation, and that attempts at their measurement in air samples from higher strata are in progress.

The following speaker, Prof. S. Chapman (London), pointed out that the chemical evidence obtained indicated that the conditions at heights somewhat above $20 \mathrm{~km}$. seem specially to favour diffusion, because of the exceptional stability of the air at those levels. This is apparently due to an upward increase of temperature for some distance above $20 \mathrm{~km}$. - a subject more fully dealt with by later speakers. It seems, however, unlikely that this diffusion process has free play at greater heights, because in this case the lightest gases, hydrogen and helium, would there entirely predominate over nitrogen and oxygen, in contradiction to the spectroscopic findings with which Prof. Chapman dealt in the main part of his address. The spectrum of the auroral light is due almost, if not entirely, to oxygen and nitrogen, and shows no trace of hydrogen or helium.

Besides revealing that the atmosphere throughout its whole content is principally a nitrogen-oxygen mixture, spectroscopic evidence has given information about the state in which these two gases are to be found. The emission spectra of the aurora and of the night-sky show bands due to molecular nitrogen; in the strongly excited auroral emission, light comes from ionized as well as neutral nitrogen molecules. Neither of the two emission spectra shows bands of molecular oxygen, but in both of them lines due to atomic oxygen are prominent. This dissociation is probably almost complete above $100 \mathrm{~km}$.; lower down, molecular and atomic oxygen coexist, and also their combined form ozone. Nitrogen is more easily ionized than dissociated by sunlight; the regular presence of ions in the upper atmosphere is indicated by radio evidence. The ions present are probably molecular nitrogen $\mathrm{N}_{2}+$ and atomic oxygen, $\mathrm{O}^{+}$; negative oxygen ions $\mathrm{O}^{-}$are also likely to be formed, by attachment of electrons to neutral oxygen atoms.

The vertical distribution of ozone was discussed in more detail by Dr. G. M. B. Dobson (Oxford). It can be found either by sending up an instrument in a balloon and measuring the amount of ozone above the instrument at any height, or by making observations from the ground. The latter method can give the information wanted if the changes in the absorption of zenith light by ozone are watched while the sun is rising or setting; from the curves thus obtained the vertical distribution of ozone can be calculated in a somewhat complicated way. It is all the more gratifying that the results agree very well with measurements made by the balloon method. Over Europe the concentration of ozone increases steadily from the ground, reaches its maximum between $20 \mathrm{~km}$. and $25 \mathrm{~km}$., and decreases rapidly at greater heights. The details of the distribution seem to depend on the geographical position and on meteorological conditions; it is not yet clear whether over America the rate of increase of ozone is the same.

The other three set speakers dealt with the closely interrelated problems of the density and temperature of the upper atmosphere.

Dr. F. J. W. Whipple (Kew) first reviewed the results obtained by direct temperature and density measurements by means of free balloons, which in general have not gone above $25 \mathrm{~km}$. although a few have reached, or slightly surpassed, $30 \mathrm{~km}$. (The frequently quoted record of an attained height of $35 \mathrm{~km}$. is probably untrustworthy, due to instrumental failure.) The lowest temperature ever recorded in the upper atmosphere was $182^{\circ} \mathrm{K}$. at a height of $16 \mathrm{~km}$. above Batavia. Such low temperatures are only found by ascents in the tropics; European ascents show in nearly every case temperatures in the stratosphere between $220^{\circ}$ and $230^{\circ} \mathrm{K}$.; in no case has any indication been found of any considerable departure from the uniformity which characterizes the stratosphere. In the lower atmosphere the density is greater in winter than in summer, but in the upper atmosphere this relation is reversed, the transition taking place at a height of $8 \mathrm{~km}$. 
In the second part of his address, Dr. Whipple discussed the use of air-waves for sounding the upper atmosphere. The fact that there are zones of abnormal audibility outside the 'zones of silence' suggests that the sound waves can travel through the air at a considerable height and then be deflected back to ground. The usual explanation given is that the uniform temperature of the stratosphere extends to some limiting height and that above that height temperature increases uniformly. The result of calculations of this kind is that the height of the trajectory of an air-wave is generally a little above $40 \mathrm{~km}$. Sometimes, when the time of passage is exceptionally long, the computed height is considerably greater, $60 \mathrm{~km}$. or more, but in such cases the results are more open to doubt. The velocities found for the waves correspond with temperatures averaging about $280^{\circ} \mathrm{K}$. at $40 \mathrm{~km}$., $310^{\circ} \mathrm{K}$. at $45 \mathrm{~km}$, and $335^{\circ} \mathrm{K}$. at $50 \mathrm{~km}$.

The first proof, however, that the temperature of the stratosphere beyond heights which can be reached by sounding balloons is not constant but increases considerably, was not provided by sound observations but inferred from the heights of appearance and disappearance of meteors. Prof. F. A. Lindemann (Oxford) explained this evidence, which was found by him and Dr. Dobson as early as 1922 . The meteor phenomena can only be accounted for by the assumption that the density of air at heights around $100 \mathrm{~km}$. is about a thousand times as great as the hypothesis of a constant temperature from the bottom of the stratosphere upwards would lead us to expect, and so the conclusion is reached that the temperature below the $100 \mathrm{~km}$. level must be considerably higher; the scarcity of meteors dis. appearing at heights of about $55 \mathrm{~km}$. was the first indication of a rapid rise of temperature in this region. Not only the sound phenomena discussed by Dr. Whipple, but also recent optical observations by $F$. Link on the variation of the zenithal brightness of the sky during the twilight hours are in excellent agreement with the meteor evidence.

Dr. E. V. Appleton (London) gave an account of the structure of the higher atmosphere as elucidated by the radio-physicists. In the radio exploration of the ionosphere two quantities are measured, namely, the height of reflection and the coefficient of reflection. Both quantities yield information of interest.

From the measurement of the heights of reflection on different frequencies, the electronic structure of the various layers can be deduced, from which it is possible to estimate the values of the 'scale height' $H$ at the appropriate levels. A thick layer is produced by the absorption of 'solar radiation if the atmospheric density varies slowly with height (large $H$ ) and vice versa. There is evidently some factor operative which brings about an increase of $H$ between $100 \mathrm{~km}$. and $300 \mathrm{~km}$., for at the level of the $E$ Layer $(100 \mathrm{~km}$.) the scale height is found to be $11 \cdot 0-11 \cdot 5 \mathrm{~km}$., whereas at the level of the $F$ Layer $(300 \mathrm{~km}$.) the scale height is $40-50 \mathrm{~km}$. An increase of scale height can only be the result of an increased temperature or of the presence of a light atmospheric constituent such as helium. The former is considered by Dr. Appleton to be the more likely; the calculated temperatures are $385^{\circ} \mathrm{K}$. for the $E$ Layer and about $1400^{\circ} \mathrm{K}$. for the $F$ Layer. Measurements of the reflection coefficient of radio wave yield approximate values of the air density at the level of reflection. These indicate molecular densities of $10^{12}$ and $10^{10}$ at the levels of Layers $E$ and $F$ respectively.
From the evidence from sound described by Dr. Whipple, it seems necessary to assume temperatures of more than $330^{\circ} \mathrm{K}$. at $50-60 \mathrm{~km}$. height. Since radio observations indicate a temperature rising from a lower degree than that at about $90 \mathrm{~km}$., there should be a temperature fall between $60 \mathrm{~km}$. and $90 \mathrm{~km}$. Recent radio experiments seem to show directly that at a height of $75 \mathrm{~km}$. there is a temperature of only $200^{\circ} \mathrm{K}$. The technique applied in the study of this region (the use of wireless waves of about $18 \mathrm{~km}$. length) was only touched upon by Dr. Appleton, but described in greater detail by Mr. J. A. Ratcliffe (Cambridge) in the course of the general discussion which followed the introductory addresses.

Another important contribution to the general discussion was made by Dr. D. F. Martyn from Australia. He communicated the results of 19 months' continuous observations of the maximum ionization densities of the $F_{2}$ region, carried out at half-hourly intervals in two stations in Australia, which seem to prove a connexion between this ionization and the meteorological conditions at the ground. This relationship can, in Dr. Martyn's opinion, scarcely be explained by changes in the temperature of the upper atmosphere. The most likely explanation appears to be that there exist large-scale movements of air in the high atmosphere in parallel with the main air mass movements at low levels-that, for example, a large influx of tropical air at low levels is accompanied by an influx of air of special characteristics (probably high humidity and/or low ozone content) at the very high levels up to $250 \mathrm{~km}$.

For those attending the meeting, it must have been satisfactory to learn that the items of information obtained by such widely different methods about the conditions in the upper atmosphere can be put together into a consistent picture. There are still many gaps to fill, due not only to the scarcity of the material yet collected but also to the obvious limitations of the methods; while the sampling and direct measuring is confined to the heights which sounding balloons can attain, the optical, acoustical and electrical methods can only reveal the chemical and physical state of certain heights in which peculiar phenomena occur. It is, on the other hand, very gratifying to see that where overlapping occurs, the results obtained by entirely independent methods corroborate each other or, at least, are not contradictory. One can, therefore, attempt to summarize the main points of our present-day knowledge of the composition, temperature and density of the upper atmosphere, as reflected in this discussion.

The atmospheric gases (with the exception of water vapour, ozone and radon) are present in constant proportion up to the height of approximately $20 \mathrm{~km}$. Between $20 \mathrm{~km}$. and $30 \mathrm{~km}$. the helium content increases, the oxygen content decreases by a fow per cent, but there is no indication that this separation process of light and heavy gases becomes more marked with height: the total atmosphere is essentially a nitrogen-oxygen mixture. Under the influence of sunlight these two gases are ionized, and oxygen dissociated, so that the higher atmosphere consists mainly of nitrogen molecules and oxygen atoms, while lower down there is also molecular oxygen and ozone. Ozone has its highest concentration per volume at about $25 \mathrm{~km}$.

The temperature decreases fairly regularly from the ground level upwards, assumes (in the latitude of 
Great Britain) at $10-11 \mathrm{~km}$. height a value of about $220^{\circ} \mathrm{K}$. which remains constant to at least $30 \mathrm{~km}$. From a few kilometres below $40 \mathrm{~km}$. upwards, the temperature increases until it reaches at $50-60 \mathrm{~km}$. more than $330^{\circ} \mathrm{K}$., whereupon it falls again, to a lower level than that of the stratosphere; the minimum, of about $200^{\circ} \mathrm{K}$., is reached between $70 \mathrm{~km}$. and $90 \mathrm{~km}$. From here onwards the temperature rises again ; at $100 \mathrm{~km}$. it is about $380^{\circ} \mathrm{K}$., at
$300 \mathrm{~km}$. it is in the neighbourhood of $1400^{\circ} \mathrm{K}$., and may increase still further with height.

Thanks to the rise in temperature from $40 \mathrm{~km}$., and again from about $90 \mathrm{~km}$. onwards, the density of the atmosphere is much greater above these heights than would be caused by gravity distribution if the temperature of the stratosphere remained constant. At $100 \mathrm{~km}$. it is of the order of $10^{12}$ molecules/c.c., at $300 \mathrm{~km}$. it is still $10^{10}$ molecules/c.c. F. A. Paneth.

\section{Institution of Gas Engineers}

$\mathrm{T}$ HF seventy-sixth annual general meeting of the Institution of Gas Engineers, held in London during June 6-9, was noteworthy as the centenary of the death of William Murdoch, the versatile Scot, who is acclaimed as the father of the British gas industry. Mr. Robert Robertson, engineer and manager of the Bristol Gas Co., presided.

In a symposium on the present and future prospects of the town's gas industry, eleven Dominion and Overseas engineers, describing the conditions in their own countries, revealed that the idea of distilling coal for lighting gas arose in several places, but it was recognized that no one deserves more credit than Murdoch for establishing the practicability of coal gas manufacture.

These contributions showed that in every country the rise of newer industries such as those of oil and electrical supply has exerted an influence on the use of gas in certain directions, accentuated by the greater efficiency of appliances. Nevertheless, the merits of a clean gaseous fuel has sufficed not merely to maintain but also to increase the consumption of gas even in those countries where all coal must be imported while hydro-electric power is abundant. The president of the Swiss Gas Association, for example, says that in spite of the great financial efforts of the electrical industry, the Swiss housewife appreciates the value of the gas flame with its instantaneous heat, its great power and quality of being visibly regulated within wide limits.

In Norway the need for coke has a dominating influence, and the gas industry can supply only 8 per cent of the country's needs. Large losses, apparently. have been incurred there by too optimistic investments of public funds in hydro-electric works in the erroneous belief that the power so generated might replace gaseous fuel.

The president's address-a review of the development of the gas industry-contained a notable announcement of a new departure in its policy of organized research. In this, the industry has been a pioneer, for thirty years ago-long before the days of research associations--the Institution began the practice of supporting co-operative research. During this time it has furthered a programme of research done at the University of Leeds, and the president's address referred to nearly fifty reports issued from this source. In the meantime, many gas undertakings, contractors and associations concerned with by-products have produced an increasing volume of experimental work. It is estimated that about a quarter of a million pounds in the aggregate is spent annually in development work. Nevertheless, such is the state of flux in the utilization of fuel that a widening of the organization of research is projected.
Until recently, investigation could be confined to established practice of making and using gas, but to-day the industry is seeking to widen the range of coals suitable for gas making and to convert these into solid, liquid and gaseous fuel in any desired proportion-even to complete gasification by the use of high-pressure technique. It is now proposed to establish a Gas Research Board supported by the subscriptions of gas undertakings and manufacturers of plant and appliances. The first president will be Sir David Milne Watson, and a director of research will be appointed. The Board will be constituted so as to qualify for Government grants if and when this is thought desirable. It is proposed to use the facilities available in existing institutions - at least in the immediate future. The functions of the Board will be: (1) the collection and dissemination of information concerning research of interest to the gas industry, (2) the provision of contact and co-ordination between research workers similarly engaged, (3) the observation and reporting of work in progress and (4) planning and arranging of future work.

Dr. E. F. Armstrong gave a lecture in memory of Murdoch tracing the growth of the gas industry and speculating on its prospects.

Non-technical readers would be interested in a paper by L. W. Andrew and A. Barrow on comfort heating by gas. To-day gas is being increasingly sold on two-part tariffs which encourage the freer use for major heating and raise the question as to the extent to which it can replace solid fuel for continuous heating. The advantages of cleanliness, flexibility and reduction of labour have long been recognized, particularly for intermittent heating. For central heating, solid fuels, especially coke, have appeared to show an unassailable advantage, but coal gas is increasingly entering this field when cleanliness, high rent and automatic control offer sufficient inducement. 'Central heat' is normally conveyed by means of hot water, but 'central' heat can more cheaply and simply be conveyed in a potential form as coal gas, and the problem to-day is to devise means for converting this into effective and acceptable sensible heat.

'T'he paper distinguishes between 'warmth' and 'comfort'. For comfort, it would appear to be desirable to have air at $50-60^{\circ} \mathrm{F}$. in movement without perceptible draught, supplemented by radiant heat received on the front of the body from an incandescent source. Shorter infra-red rays of length below $3 \mu$ capable of penetrating the skin, according to $\mathrm{L}$. Hill, are of particular value. In addition, tradition in Great Britain requires an open fire with the character associated with the open coal fire. The authors believe that these requirements can be met by 